\title{
THE ROLE OF PUSH AND PULL MOTIVATIONS IN BRANDING FOR RURAL TOURISM: LAKE TISZA COMPLEX PROJECT
}

\author{
Damla Bal ${ }^{1}$ \\ Éva Erdélyi ${ }^{2}$ (1)
}

DOI: https://doi.org/10.31410/LIMEN.2019.121

\begin{abstract}
The aim of this study is to understand the push and pull travel motivations of domestic tourists in Hungary and examine its importance in building a positive destination brand of Lake Tisza region that will affect the decision process of the individuals. An interview was done with Tisza office to have a closer look to the development project of Lake Tisza; the existing brand image of the region was examined through destination observation and several on-site interviews. The data, collected through an online questionnaire and analysed using different statistical methods, shows that the push motivation which is relaxing away from the ordinary life is the most important for the domestic tourists in Hungary; nevertheless, the pull motivations are the basis which triggers the push motivations. It is suggested to brand the destination attributes of Lake Tisza region as a way of relaxing away from the ordinary life.
\end{abstract}

Keywords: Push and Pull Motivations, Rural Tourism, Branding.

\section{INTRODUCTION}

$\mathrm{D}^{2}$ evelopment of tourism activities in the rural regions has a substantial position in the national strategies of counties. Hungary has a development project which is called as Lake Tisza Complex Project targeting an increase in the numbers of visitors. It is highly significant to create a brand to be different from competitors in order to gain high profits and grow in a competitive environment that intensifies with the development of technology in the global market. A brand is an important tool for the marketing of the destinations and its services. In order to gain a positive and long-term place in the minds of individuals, destinations focus on brands as a powerful resource that can influence the decision process of tourism consumers.

It is known that the concept of brand is not only a phenomenon that has gained importance in today's competitive environment; but also, in the old times the pictures and symbols were used to distinguish the products from each other. Branding theory was first introduced in 1950s in the context of consumer products; however, in 1990s branding was developed going beyond to its limits in that context and started being applied to brand owning corporations (Kavaratzis, Warnaby, and Ashworth, 2015). Branding, which was initiated on the ground of determining the responsibility for the product, has become a competition issue in which businesses emphasize their superiority over each other.

A brand is a wide-ranging term, and many of the characteristics that determine the goods fall within the scope of the brand. American Marketing Association, AMA Dictionary defines the brand as "a name, term, design, symbol or any other feature that identifies one seller's good or

\footnotetext{
$1 \quad$ Budapest Business School - University of Applied Sciences, H- 1054 Budapest, Alkotmány utca 9-11, Hungary

2 Budapest Business School - University of Applied Sciences, H- 1054 Budapest, Alkotmány utca 9-11, Hungary
} 
service as distinct from those of other sellers." International Organization for Standardization (ISO) adds that "a brand is an intangible asset that is intended to create distinctive images and associations in the minds of stakeholders, thereby generating economic benefit/values." However, the brand is composed of many dimensions such as emotional benefits, user imagery and as well as the basic features of the product (Aaker, 1996, p.74). Another definition of brand is "a sign or set of signs certifying the origin of a product or service and differentiating it from the competition" (Kapferer, 2008). In accordance with Moilanen and Rainisto's definition, "a brand is an impression perceived in a client's mind of a product or a service. It is the sum of all tangible and intangible elements, which makes the selection unique" $(2009, \mathrm{p} .6)$.

Branding is a marketing practice that provides significant benefits for product owners, agents and consumers. The brand is an element that gives consumers the convenience and confidence in terms of quality to recognize and distinguish the products that they will buy. Consumers' perception of the brand and their confidence in the brand are important in the development of the product owners' business image. For this reason, the brand is an important image element of the product owner. For agents selling with a specific brand name, the brand is effective in generating demand because of that consumers want to take advantage of the benefits of brands.

Since building and managing the value of a brand as the main source of success are increasingly fundamental today, destination managers need to focus on the main components of brand and develop these components in line with the travel motivations of the individuals in the long term. Travel motivations play an important role in generating tourism products for tourists, have a relationship with the satisfaction of the tourists and contribute to the understanding of decision process of tourists (Crompton and McKay, 1997, cited in Kassean and Gassita, 2013).

In accordance with Dann (1997), who's "the push and pull theory of motivations is widely accepted in tourism research, multiple factors motivate tourists to visit particular places or destinations, but these factors can be categorised as either push or pull motivations" (Yousaf and Amin, 2018). In the literature push factors stands for the internal feeling that drives individuals to take travel decisions, on the other hand pull motivations are related to the attractiveness of the destinations that leads individuals to travel.

Crompton (1979) works on a theoretical framework based on Dann's (1977) study and finds the following influencing push motivations; "the desire for escape from a perceived mundane environment, rest and relaxation, prestige, regression, health and fitness, adventure and social interaction, enhancement of kinship relationships, exploration and evaluation of self, excitement" (Kassean and Gassita, 2013). Yuan and McDonald (1990) determine five push factors out of 29 motivational items in their study focusing on the four countries; and the push factors, what they identify, are "escape, novelty, enhancement of kinship relationships, prestige, relaxation/ hobbies" (Kassean and Gassita, 2013). Pearce (2002) also develops a framework which lists push motivations as "novelty, escape/relaxation, self-actualization, nature, self-enhancement, romance, kinship-belonging, autonomy, self-development (host-site involvement), nostalgia, stimulation, isolation and recognition" (Kassean and Gassita, 2013).

"The push factors can be summarized as factors encouraging people to travel, representing individuals' socio-psychological needs; in contrast, pull factors are mostly related to destinations' amenities, for example, service quality, prices and infrastructure" (Yousaf and Amin, 2018). Weaver and Lawton (2012) recommend that the pull motivation factors can be categorised as 
"geographical proximity to markets, accessibility to markets, availability of attractions, cultural links, availability of services, affordability, peace and stability, positive market image, pro-tourism policies" (Camillo, 2015).

This research has been designed to determine the push and the pull motivations of domestic tourism consumers in Hungary to provide guidance in developing the effectiveness of Lake Tisza destination brand. This paper will contribute to the theoretical framework by measuring the push and the pull travel motivations of domestic tourists in Hungary, and finding a strategy to increase the brand awareness. The study aims to provide suggestion for increasing the effectiveness of marketing activities focusing on Lake Tisza Complex Project brand.

Based on destination observations done in the summer-autumn period of 2019, it is seen that the region has huge potential for the development of tourism activities and tourists who enjoy nature \& calm atmosphere and being physically active. First, the number of cyclists draws attention that it is getting higher and higher. According to the interview with the director and international relations officer of Tisza Office, the number of cyclists has increased $\% 50$ comparing the previous year. In the light of data, which is taken from Tisza office, total number of cyclists were 30.884 in 2017; on the other hand, total number of cyclists were 56.959 in 2018. In 2019, the number is 39,739 which represent the cyclists between January and August. Additionally, ongoing development projects for the region are mentioned during the interview: fish pass (which is an ecological project aiming the restoration of the fish migration paths in Danube), development of marinas, import of holiday boats, development of cycle path, development of walking and hiking path. It is said that the walking path is in a bad condition in the winter season and rainy weathers. The project aims to solve this problem in order to provide better service to the local people and tourists.

Based on the on-site interviews, Tisza region is not popular as much as Lake Balaton, because of the marketing activities. There is an image that Lake Balaton is fancier than Lake Tisza because of the infrastructure, vineries and small-sized mountains. However, they mention that Lake Tisza is more untouched and has lots of green areas and good for big families. Additionally, it is told that the music festival which is organised every year has a good image for them that is one of the attributes of the cognitive image and the other mentioned attributes are calm atmosphere, fishing, canoe, and cycle area. They see the National Park as an advantage to the destination because it is very close to Lake Tisza. Regarding the affective image of the destination, they mention that it depends on the time spent there and it is decided that Lake Tisza does not have any strong affective and unique image yet.

In order to reach the local people and Tisza Lake lovers, the questionnaire was shared on many Facebook group which are related to the Tisza region. Surprisingly, the owner of one of those Facebook group contacted with me and provided information regarding the issue. In light of her view, there are a lot of foreign people who has cottages in the region. The common nationalities are Dutch, Belgian and German. Interestingly, during the observation period it was seen that some restaurants have German menu instead of English; and, there were a lot of German speaking people sitting in the restaurants.

123 valid answers are collected through an online questionnaire and results are analysed using different statistical methods. Based on results, woman respondents are $49,59 \%$ of the respondents and man respondents represent 50,41\%. 25-34 old years respondents consist of 54,47\%, and 
18-24 years old respondents constitute $28,46 \%$ of the sample group. $57,72 \%$ of the sample group live in Budapest. 39,84\% of them have bachelor's degree while $36,59 \%$ of the respondents have master's degree. $42,28 \%$ of the respondents are single, and $35,77 \%$ of the respondents are in a relationship. $21,95 \%$ of the respondents are married. $86,18 \%$ of the respondent do not have any child. $43,90 \%$ of the respondents are full-time employed and $21,14 \%$ of respondents are students. $65,04 \%$ of the respondents have medium income level.

In order to summarise the collected data, mean is used that is one the measures of central tendency (Nicholas, 1999, p. 14). The mean, which is also called as the "average, is calculated by adding all the figures within the data set and then dividing by the number of figures within the set" (Kenton, 2019). Based on the mean calculations of the data, the relative importance of pull travel motivations for the Hungarian domestic tourists are displayed below.

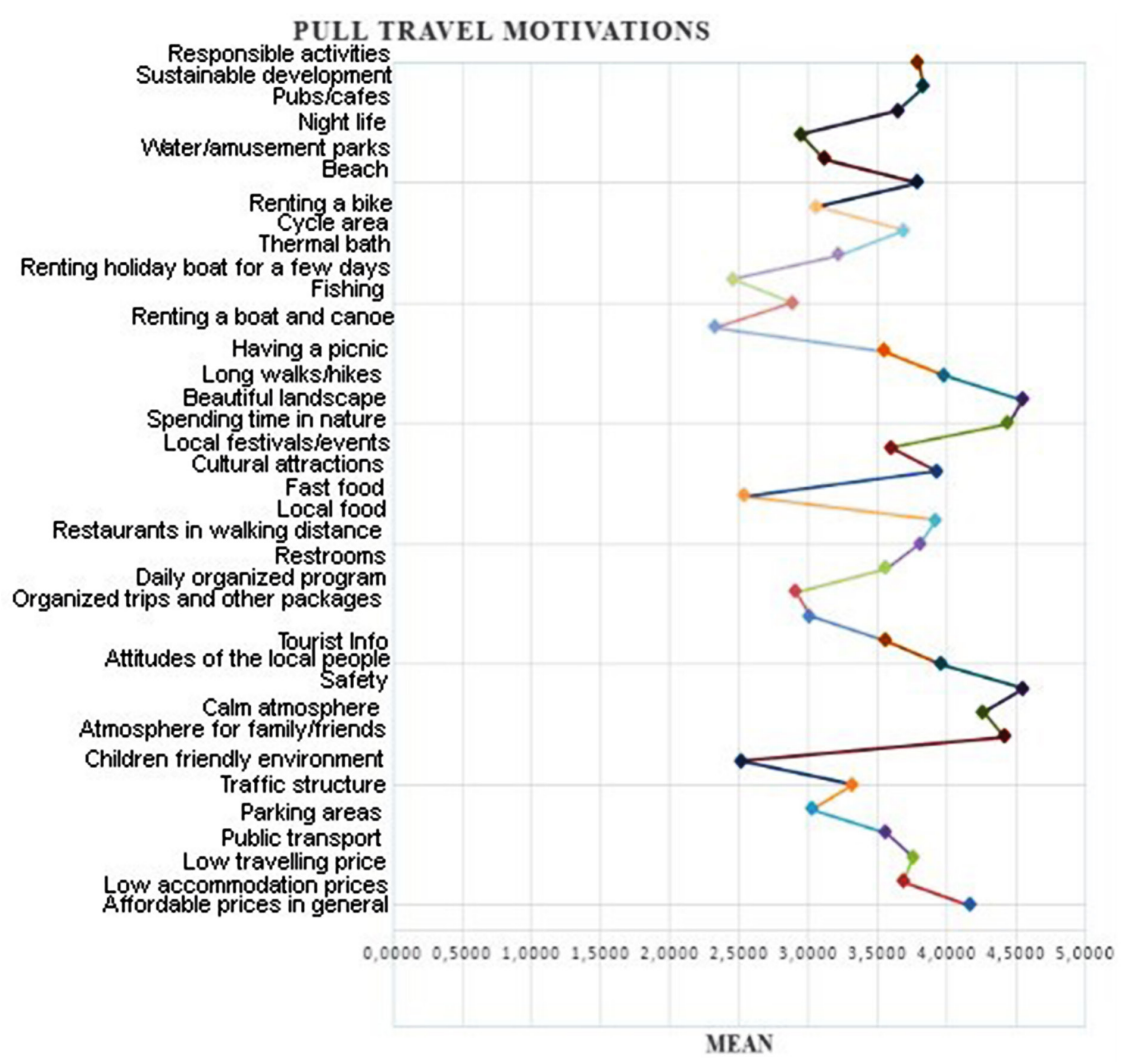

Figure 1. Mean calculations of the pull motivations.

Source: Own Source

As one can see from the above figure that there are statistical differences between the pull travel motivations of the respondents. The most important factor is safety that $\% 69,9$ of the respondents choose as very important. Respectively the other "very important" pull motivation factors are beautiful landscapes for $\% 67,5$ of the respondents, spending time in nature for $\% 58,5$ of the respondents, destinations' opportunities for family \& friends to have a good time for $\% 63,4$ of the respondents level, calm atmosphere for $\% 47,2$ of the respondents and affordable prices in general for $\% 46,3$ of the respondents.

In order of long walks \& hikes, attitudes of the local people, cultural attractions, local food, sustainable development, restaurants in walking distance, beach, responsible activities are very close to important level for the respondents; besides, low traveling prices, cycle area, low ac- 
commodation prices, pubs \& cafes, local festivals \& events, public transport, tourist info, restrooms, having a picnic are also close to important level even though it is not as strong as previously mentioned attributes of pull motivations.

Afterwards, traffic structure, thermal baths, water \& amusement parks, bike rental, parking areas, organized trips and other packages, night life, daily organized programs, fishing have neutral impact on the sample group. Fast food, children friendly environment, holiday boat rental for a few days, boat \& canoe rental have less importance for the respondents. However, as the sample group is not composed of families with children, one can assume that the result might not show the importance of children friendly environment. On the other hand; it is useful to see that for the people who do not have any child, children friendly environment is not important.

Public transportation accessibility is much more important for younger people, especially who are between 25-34 years old. \%38 of 25-34 years old respondents see it as very important and \%20 ,80 of 25-34 years old respondents see it as important. \%40,63 of the 18-24 years old respondents mark it as very important. Due to the low participant of aged people, it is decided to put together the number of respondents who are over 35 years old. Based on that, \%14,30 of over 35 years old respondents see the accessibility of public transportation as very important. However, parking areas are more important for the elderly respondents. As \%35 of over 35 old years respondents mark parking areas as very important and \%19,20 percent of them see it as important. Interestingly, $\% 8,65$ of 25-34 years old respondents see the parking areas as very important; however, for the majority of them (\%40) parking areas are neither important nor unimportant. For \% 15,75 of 18-24 years old people, parking areas are very important and $\% 28,3$ of them decide that it is important.

Mean method is also used to summarize the collected data and by the help of the excel program the below graph is created.

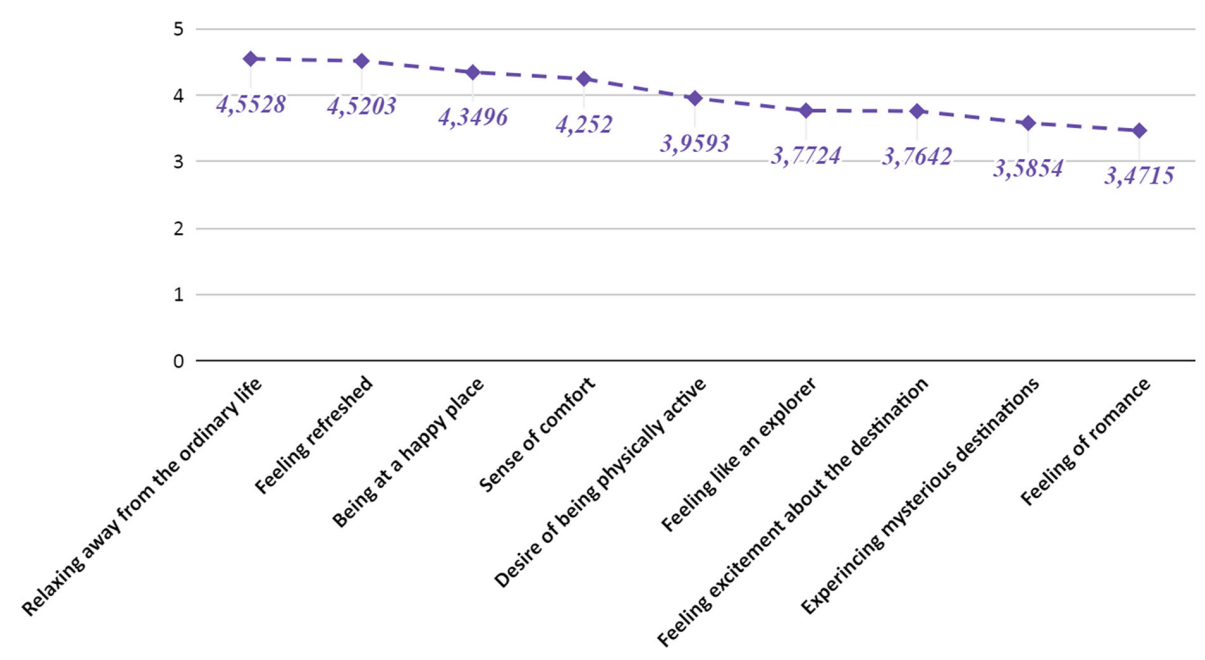

Figure 2. Mean calculations of the push motivations

Source: Own Source

It is seen that relaxing away from the ordinary life is the most encouraging push motivation that for $\% 67,5$ of respondents mark it as very important. Additionally, feeling refreshed is very close to the relaxing away from the ordinary life. The other pull motivations which are important are being at a happy place and sense of comfort, desire of being physically active. Addition to this, feeling like an explorer, feeling excitement about the destination, and feeling romance have relatively importance. 
In compliance with correlation calculations of demographic characteristics of the respondents and the push motivations on SPSS program, it is seen that household income level correlates with the motivation of relaxing away from the ordinary life. For $\% 69$ of respondents who have medium income level, relaxing away from ordinary life is very important and \%66,70 of respondents with low income level see relaxing away from ordinary life as very important. Additionally, $\% 23$ of respondents with medium income level mark this pull motivation as important; and for $\% 25$ of respondents who has a low-income level relaxing away from ordinary life is important.

Another surprising result is that for the respondents who travel with friends the importance of feeling excitement about a rural destination has higher importance; and who travel with family feeling excitement is relatively important. \%19 of respondents who travel with family vote for very important and \%38,60 of them vote as important regarding the importance level of feeling excitement; \%52 respondents whose travel mates are friends see this motivation as very important and $\% 28$ of them decide that it is important. For the solo travellers it is not very important motivation as just $\% 19$ of them thinks it as very important and $\% 38$ of them see it as important.

The motivation of experiencing mysterious destinations is also respectively important for the respondents who travel with friends and family. $\% 48$ of respondents whose travel mates are friends see this motivation as very important and \%24 of them see it as important. \%17 of respondents who travel with family thinks it as very important and for $\% 32,50$ of them experiencing mysterious destinations is important. $\% 12,50$ of the solo travellers it has very importance and $\% 38$ of them see it as important; however, for the majority of solo travellers $(\% 45)$ it is neither important nor unimportant.

Enigmatically, the motivation of feeling romance in the destination is not important for married respondents. $\% 36$ of married respondents think that it has a neutral impact on their decision-making process. For $\% 45,50$ of respondents who are in relationship romantic image of the destination is important and $\% 21,50$ of them it has very significance. Although $\% 31,50$ of single respondents see it as neutral, for $\% 29$ of them it has importance and for $\% 22,40$ of single respondents it is very important.

\section{CONCLUSION}

To sum up, based on the questionnaire results, the most important pull motivation is safety that $\% 69,9$ of the respondents mark it as very important. In order of the other very important pull motivations are beautiful landscapes for $\% 67,5$ of the respondents, spending time in nature for $\% 58,5$ of the respondents, destinations' opportunities for family \& friends to have a good time for $\% 63,4$ of the respondents level, calm atmosphere for $\% 47,2$ of the respondents and affordable prices in general for $\% 46,3$ of the respondents. The most important push motivation is relaxing away from the ordinary life for $67,5 \%$ of the respondents and the second very important push motivation is feeling refreshed in the countryside for $64,2 \%$ of the respondents. In the light of these results, it is suggested that the branding activities of the Lake Tisza Complex Project have to involve influential aspects to trigger those six pull motivations and two push motivations of the domestic tourists in Hungary to affect their travel decisions. Especially, the destination attributes need to be branded as a way of relaxing away from ordinary life and relaxing in the nature.

It is expected that the marketing directors and the managers of the project will take advantage of this study. For the next study, the researcher aims to build the whole marketing plan of Lake Tisza Complex Project. 


\section{REFERENCES}

Aaker, D. A. (1996). Building Strong Brands. New York: Free Press.

AMA. (2014). What is Marketing? - The Definition of Marketing - AMA. American Marketing Association. Retrieved from https://www.ama.org/the-definition-of-marketing-what-is-marketing/.

Camillo, A. (2015). Handbook of research on global hospitality and tourism management. Information Science Reference.

Franzen, G., Moriarty, S. (2008). The Science and Art of Branding. Google Books. Retrieved from https://books.google.com.tr/books?id=XrcqlxhzdHQC\&printsec $=$ frontcover $\# \mathrm{v}=\mathrm{o}-$ nepage $\& \mathrm{q} \& \mathrm{f}=$ false.

Kapferer, J. (2008). The New Strategic Brand Management - Jean Noel Kapferer. Retrieved from https://www.academia.edu/12869300/The_New_Strategic_Brand_Management_-_ Jean_Noel_Kapferer_PDF_

Kassean, $\bar{H}$. and Gassita, R. (2013). Exploring tourists push and pull motivations to visit Mauritius as a tourist destination. Tourismos: An International Multidisciplinary Journal of Tourism, 8(2), pp. 39-56.

Kavaratzis, M., Warnaby, G. and Ashworth, G. (2015). Rethinking Place Branding - Comprehensive Brand Development for Cities and Regions. Springer. Retrieved from https:// www.springer.com/gp/book/9783319124230.

Kenton, W. (2019). Descriptive Statistics. Investopedia. Retrieved from https://www.investopedia.com/terms/d/descriptive_statistics.asp

Marketing-dictionary.org. (2018). Brand |Common Language Marketing Dictionary. Retrieved from https://marketing-dictionary.org/b/brand/.

Moilanen, T. and Rainisto, S. (2009). How to Brand Nations, Cities and Destinations. London: Palgrave Macmillan UK.

Nicholas, J., \& Mathematics, S. (1999). Introduction to descriptive statistics. Mathematics Learning Centre, University of Sydney.

Roy, D. and Banerjee, S. (2014). Identification and measurement of brand identity and image gap: a quantitative approach. Journal of Product \& Brand Management, 23(3), pp.207-219.

Yousaf, A., Amin, I., \& Santos, J. (2018). Tourist's Motivations to Travel: A Theoretical Perspective on the Existing Literature. Tourism and Hospitality Management; 24(1), 1-15 